\title{
Silica-Based Membranes with Molecular-Net-Sieving Properties: Development and Applications
}

\author{
Toshinori Tsuru \\ Department of Chemical Engineering, Hiroshima University, 1-4-1 Kagamiyama, Higashi-hiroshima-shi, \\ Hiroshima 739-8527, Japan
}

Keywords: Inorganic Membranes, Silica, Organosilica, Separation, Gas, Pervaporation, Reverse Osmosis

\begin{abstract}
Over the past several decades, inorganic membranes composed of zeolite, silica, carbon, and metal/organic frameworks (MOF) have improved dramatically in terms of fabrication and application. Pure silica $\left(\mathrm{SiO}_{2}\right)$ and organosilica membranes for use in molecular separation are the focus of this review. First, the fabrication of these silica-based membranes is outlined to highlight the great progress achieved in sol-gel and CVD processing. Then, applications in gas- and liquid-phase separations and an evaluation of pore sizes are summarized and future perspectives are discussed.
\end{abstract}

\section{Introduction}

Polymeric membranes have a long history of intensive investigation, and they have achieved successful applications that include liquid and gas-phase separation. Inorganic membranes, which are thermally and mechanically stable, have been investigated from the 1980's, and the first International Conference on Inorganic Membranes (ICIM) was held in 1989 in Montpellier, France. The typical structures of thermally and mechanically stable inorganic membranes are summarized in Figure 1. Early-stage study on inorganic membranes in the mid-1980's focused on membranes with large pore sizes with granular structures. Therefore, applications tended toward forms of filtration such as MF and UF using $\mathrm{Al}_{2} \mathrm{O}_{3}, \mathrm{TiO}_{2}$, and $\mathrm{ZrO}_{2}$, some of which have been successfully commercialized and applied to practical applications. Application of inorganic membranes to gas separation was initiated in 1980 by pioneering works on carbonized membranes. Successful separation of $\mathrm{H}_{2}$ was reported using $\mathrm{SiO}_{2}$ membranes prepared by CVD (Gavalas et al., 1989) and by sol-gel processing (Kitao et al., 1990). In addition, $\mathrm{NaA}$ hydrophilic and silicalite hydrophobic zeolite membranes with ordered structures were reported in the early 1990s. Inorganic membranes showed stability as well as high performance (high flux and selectivity), which intensified the research on inorganic membranes. Very recently, new materials such as metal organic frameworks (MOF) and carbon-based materials such as carbon nanotube (CNT) and graphene/graphene oxide have shown high performance in gas and liquid phase separation. Metal oxide, often mentioned as ceramics such as $\mathrm{Al}_{2} \mathrm{O}_{3}, \mathrm{SiO}_{2}, \mathrm{TiO}_{2}, \mathrm{ZrO}_{2}$, and

Received on July 11, 2017; accepted on August 22, 2017

DOI: $10.1252 /$ jcej.17we235

Correspondence concerning this article should be addressed to T. Tsuru

(E-mail address: tsuru@hiroshima-u.ac.jp).

Presented at The 5th ASCON-IEEChE 2016 at Yokohama, November 2016 composites, are prepared via sol-gel processing and chemical vapor deposition (CVD), which includes thermal CVD and plasma-enhanced CVD (PECVD).

As shown in Figure 2, the tunable pore sizes of inorganic membranes are, in general, dependent on the types of materials. For example, the smallest pore size of $\alpha-\mathrm{Al}_{2} \mathrm{O}_{3}$, although it is most widely used for porous ceramic membranes due to its high stability, is approximately $100 \mathrm{~nm}$. Separation of molecules typically requires a size that is less than $1 \mathrm{~nm}$, and this has been accomplished using zeolite, carbon, and silica-based materials. Silicon oxide (silica, $\mathrm{SiO}_{2}$ ) membranes have been most extensively reported due to a variety of advantages (Tsuru, 2001, 2008, 2011). Silica confers great advantages with its thermal stability, and in the controllability of pore sizes that range from subnano to several nanometers. More importantly, silica remains an amorphous structure up to $1,000^{\circ} \mathrm{C}$, so that the amorphous networks are responsible for molecular separation, while

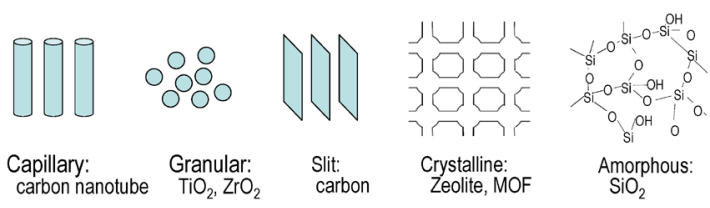

Fig. 1 Porous structures of inorganic membranes

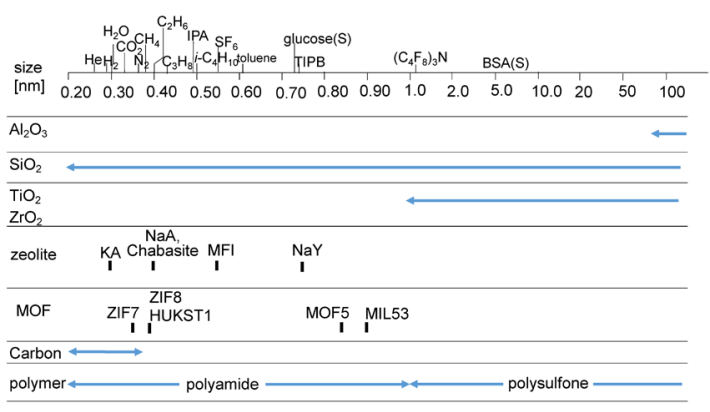

Fig. 2 Membrane materials and pore/molecular sizes 
most metal oxides such as $\mathrm{TiO}_{2}$ and $\mathrm{ZrO}_{2}$ show granular structures and are crystallized at $400-600^{\circ} \mathrm{C}$, which enlarges pore size during the phase change. Silica is rather flexible compared with other types of metal oxides, and is relatively amenable to the formation of ultramicro/nanoporous membranes with pore sizes of less than $1 \mathrm{~nm}$, which makes it possible to separate gas mixtures such as hydrogen. On the other hand, the flexibility of silica networks causes silica membranes to suffer from densification under hydrothermal conditions, which results in decreased permeance compared with dry conditions. Organosilica, which includes hybrids of silica with organic compounds, has been extensively investigated almost from the beginning of the development of inorganic membranes. Since the development of organosilica using bridged alkoxysilanes, which will be introduced later, research has accelerated extensively (Agirre et al., 2014; ten Elshof and Dra, 2016).

This review is focused on silica-based membranes for molecular separation, which includes both pure silica $\left(\mathrm{SiO}_{2}\right)$ and organosilica. First, fabrication of silica-based membranes is summarized, which highlights the great progress made in sol-gel and CVD processing. Then, applications in gas and liquid phase separation and evaluation of pore sizes will be reviewed.

\section{Fabrication of Silica Membranes}

Porous separation membranes must consist of pores continuously connected from the feed to the permeate stream; otherwise, no permeation through the membranes could occur. Figure 3 shows the typical structure of porous ceramic membranes. Supports, which are usually fabricated from metal oxide powders such as $\alpha-\mathrm{Al}_{2} \mathrm{O}_{3}$ by extrusion or slip casting, show pore sizes typically larger than $1 \mu \mathrm{m}$ and a thickness in millimeters for mechanical strength. An intermediate layer, mostly prepared from $\gamma-\mathrm{Al}_{2} \mathrm{O}_{3}$ or $\mathrm{SiO}_{2}-\mathrm{ZrO}_{2}$, is coated onto the support layer to decrease pore sizes down to several nanometers. The separation top layer, which has separation ability and must have controlled pore sizes suitable for specific separation, is formed as thin as possible on the intermediate layer. In this way, inorganic membranes show a gradient structure that ranges from micrometers (supports) to nano/subnanometers (separation top layer) in order to minimize the resistance to permeation across a membrane.

As schematically shown in Figure 4, CVD silica membranes are fabricated either in (a) one-side CVD where all reactants are fed from one side for silica layer deposition, or (b) counter-diffusion CVD. Since a Si-precursor such as tetraethoxysilane (TEOS) and another reactant are fed separately from both sides of the substrate in counter-diffusion CVD, the deposition automatically terminates once a silica layer forms inside the pores, resulting in a thin layer formation and a reduction in pinholes. On the other hand, as shown in Figure 5, during sol-gel processing, a metal alkoxide or inorganic salt is hydrolyzed and subjected to simultaneous condensation reactions to form polymeric or

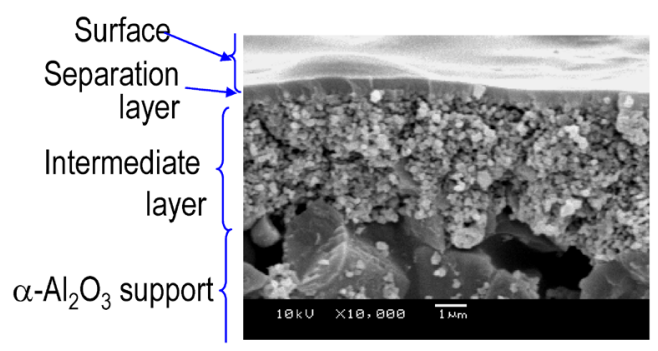

Fig. 3 Cross sectional SEM

(a) One-side CVD

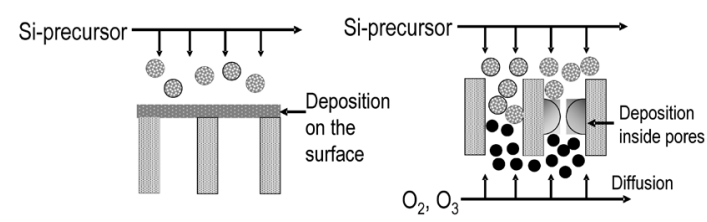

Fig. $4 \mathrm{CVD}$ of $\mathrm{SiO}_{2}$ membranes

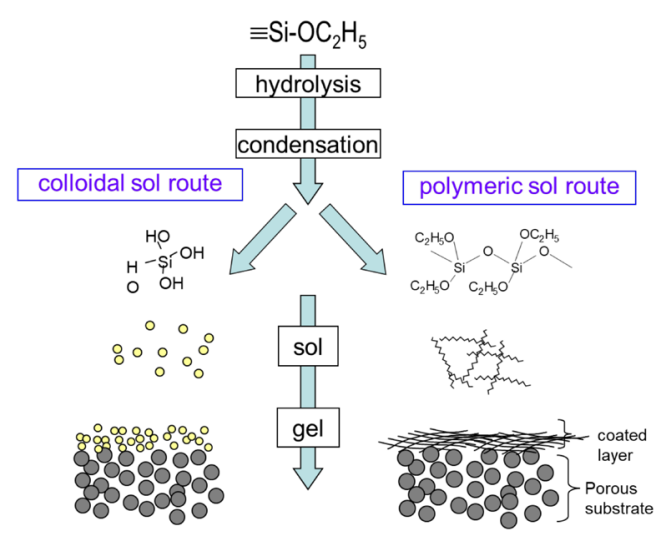

Fig. 5 Sol-gel processing of $\mathrm{SiO}_{2}$ membranes

colloidal sols, depending on the reaction conditions (type of alkoxysilane and solvent, catalyst, composition of reactants, temperature, etc.). In the polymeric sol route, the hydrolysis reaction is slower, which is generally achieved by adding a small amount of water, resulting in a partially hydrolyzed alkoxide and in the formation of a linear inorganic polymer. Colloidal sols are obtained with high rates of hydrolysis and condensation. Through the subsequent gelation process, a coated layer forms on the intermediate layer. Pore sizes effective for separation can be controlled by the void spaces among the packed colloidal solid (interparticle pore) in the colloidal sol route and by the gel network space in the polymeric gel route, which corresponds to granular and amorphous silica networks, respectively.

The most critical issues to be solved for $\mathrm{SiO}_{2}$ membranes are (1) separation performance that is affected by pore size control and defect-free thin-film formation, and (2) stability, which applies to hydrothermal stability in particular. Recent papers have focused either on one or the other of the above two issues.

Recent approaches to membrane fabrication for improv- 
Table 1 New approaches for fabricating silica-based membranes

1. Materials

Ion doping: doping cations such as $\mathrm{Ni}, \mathrm{Co}, \mathrm{Zr}$, etc. for improved hydrothermal stability, fluorine-doping for pore size control.

Organosilica: a variety of organosilicon compounds such as silsesquioxane (pendant or bridged alkoxysilane) are used for pore-size control in template or spacer methods, and for control of hydrophobicity/hydrophilicity and affinity.

Carbonized-template silica: hydrocarbon polymer was added to alkoxysilane for improved hydrothermal stability.

2. Structural control

Interlayer-free: No intermediate layer is used for reducing permeation resistance and facile processing.

Layered hybrid: Organosilica layers are coated onto polymeric substrates.

Hydrophobic intermediate layer: to avoid any capillary condensation for use in humidified atmosphere.

3. Processing

High-temperature firing: for improved hydrothermal stability. Plasma-enhanced CVD: low-pressure and atmospheric pressure CVD for silica, organosilica and carbon.

Interfacial polymerization: ammonium-type POSS (polyhedral oligomeric silsesquioxane) in water and 6-FDA (hexafluoroisopropylidene dianhydride) in toluene.

ing the separation performance of silica-based membranes are summarized in Table 1, which can be categorized from the viewpoint of materials, structure, and processing. The advances will be introduced in the following sections, and increased focus will be applied to organosilica membranes in both CVD and sol-gel processing, which have shown great success.

\subsection{Materials for the improved performance of silica- based membranes}

1.1.1 Ion-doping: cations and anions Among the various types of metal oxides, silica is rather flexible so that it is relatively easy to dope various types of ions into a silica matrix. Zr was incorporated into silica networks by co-hydrolysis of TEOS and zirconium alkoxide such as zirconium butoxide, and successfully applied to nanofiltration, pervaporation of aqueous solutions (Tsuru et al., 1998; Asaeda et al., 2002) and hydrogen separation under hydrothermal conditions (Yoshida et al., 2001). Ni and Co nitrates were mixed for hydrolysis and condensation of TEOS in sol-gel processing, and were reported to be effective in improving hydrothermal stability at $500-600^{\circ} \mathrm{C}$ under steam partial pressure of $300-400 \mathrm{kPa}$ (Kanezashi and Asaeda, 2005; Igi et al., 2008). The state of doping with cations remains unclear, but doped cations reportedly decreased the thermally induced molecular motion of a silica matrix, thereby increasing the hydrothermal stability. Anions such as fluorine are now being doped into silica networks in the form of ammonium fluoride. Doped fluoride, which bonds with Si atoms, reportedly expands the network structure, which controls for the production of larger pore sizes (Kanezashi et al., 2016).

Early on, CVD techniques adopted metal doping into sili-
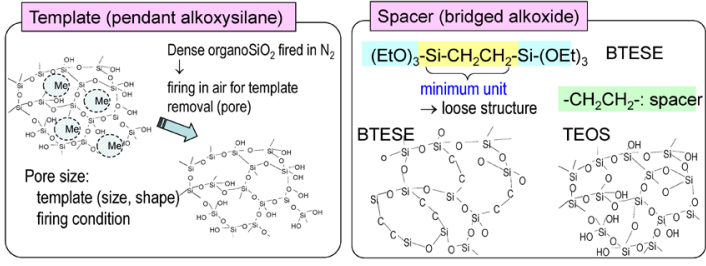

Fig. 6 Pore size control using organosilica

ca; recently, Ahn et al. (2017) prepared silica-zirconia membranes by cofeeding TEOS and zirconium tetra-butoxide, resulting in improved hydrothermal stability.

1.1.2 Organosilica in sol-gel processing TEOS is the most commonly used precursor for membranes. Due to the flexible control of both the chemical and physical structures of preparation parameters such as concentration, $\mathrm{pH}$, reaction temperatures, etc., the successful tuning of the pore sizes of TEOS-derived $\mathrm{SiO}_{2}$ membranes was made possible for hydrogen separation, which requires a pore size of less than $0.4 \mathrm{~nm}, \mathrm{CO}_{2}$ separation, and organic gas separation. Recent progress in the pore size tuning of silica-based membranes includes the utilization of silsesquioxane, which is an organosilicon compound with the chemical formula $\mathrm{RSiO}_{1.5}$ ( $\mathrm{R}=\mathrm{H}$, alkyl, aryl or alkoxyl groups). Silsesquioxane can be categorized as a pendant type such as $\mathrm{Si}-\mathrm{CH}_{3}$ consisting of organic groups directly bonded to $\mathrm{Si}$ atoms, or a bridged type such as $\mathrm{Si}-\mathrm{C}_{2} \mathrm{H}_{4}-\mathrm{Si}$ units consisting of organic linking units between two silicon atoms. Sol-gel processing offers the great advantage of low-temperature processing so that organic functional groups remain following hydrolysis and condensation reactions where they can be useful in controlling the network pore sizes and in promoting affinity with permeating molecules.

The template technique was proposed by Raman and Brinker for pore-size tuning (Raman and Brinker, 1995). As shown in Figure 6 (left), they first co-polymerized TEOS and methyltriethoxysilane (MTES), a typical pendant-type alkoxysilane, and then coated them onto an $\gamma-\mathrm{Al}_{2} \mathrm{O}_{3}$ intermediate layer, followed by firing under $\mathrm{N}_{2}$ to solidify the coated layer, and then firing under an air atmosphere to remove organic functional groups (methyl groups) to control the pore sizes. $\mathrm{CO}_{2} / \mathrm{CH}_{4}$ selectivity reached 70 with $\mathrm{CO}_{2}$ permeance of approximately $10^{-7} \mathrm{~mol} /\left(\mathrm{m}^{2} \mathrm{~s} \mathrm{~Pa}\right)$. These researchers referred to this method as a "template technique" that could be used to tune the pore sizes of silica networks. Kusakabe et al. (1999) reported silica membranes coated by TEOS mixed with octyl-, dodecyl- or octadecyltriethoxysilane, and found $\mathrm{H}_{2}$ and $\mathrm{CO}_{2}$ permeance was increased due to the removal of organic functional groups by calcinating this green membrane at $600^{\circ} \mathrm{C}$, while the permeance of large molecules was decreased as a result of shrinkage of the silica matrix.

Another strategy involves the use of functional groups of silsesquioxane to control the hydrophilicity/hydrophobicity and selective permeation. As mentioned, silica is hydrophilic, and tends to suffer from decreased permeance due to adsorbed water. de Vos et al. (1999) prepared hydrophobic sili- 
ca membranes for gas separation using methylated $\mathrm{SiO}_{2}$ sols $\left(\mathrm{Me}-\mathrm{SiO}_{2}\right)$ prepared via the co-hydrolysis and condensation reaction of methyltrimethoxysilane (MTMS) and TEOS using an acid catalyst. The $\mathrm{Me}-\mathrm{SiO}_{2}$ membrane showed very high $\mathrm{H}_{2}$ permeance $\left(1 \times 10^{-5} \mathrm{~mol} /\left(\mathrm{m}^{2} \mathrm{~s} \mathrm{~Pa}\right)\right.$ after correcting the support resistance and high selectivity of large molecules. Aminopropyl triethoxysilane (APTES) was applied for $\mathrm{CO}_{2}$ selective permeation over $\mathrm{N}_{2}$ (Xomeritakis et al., 2005). The highest $\mathrm{CO}_{2} / \mathrm{N}_{2}$ selectivity ranged from $100-200$ with $\mathrm{CO}_{2}$ permeance ranging from $1-11 \times 10^{-8} \mathrm{~mol} /\left(\mathrm{m}^{2} \mathrm{~s} \mathrm{~Pa}\right)$.

In 2008, organosilica membranes utilizing bridgedtype alkoxysilanes, which consisted of linking units, mostly organic functional groups, between two Si atoms, that were first reported by a group from Twente University, the University of Amsterdam, and the Energy Center of The Netherlands (ECN) (Castricum et al., 2008a, 2008 b). Bis(triethoxysilyl)ethane $\left(\mathrm{Si}-\mathrm{C}_{2} \mathrm{H}_{4}-\mathrm{Si}\right.$ unit, BTESE) and bis(triethoxysilyl)methane ( $\mathrm{Si}-\mathrm{CH}_{2}-\mathrm{Si}$ unit, BTESM), showed superior $n$-butanol dehydration properties and hydrothermal stability compared with conventional $\mathrm{SiO}_{2}$ membranes during pervaporation at $150^{\circ} \mathrm{C}$. Gas permeation properties of organosilica membranes were also reported (Kanezashi et al., 2009). The network pore size was successfully tuned by utilizing BTESE, which showed high $\mathrm{H}_{2}$ permeance with high selectivities of $\mathrm{H}_{2}$ /organic compounds such as propane and toluene (Niimi et al., 2014; Yu et al., 2016), since the linking portion $\left(\mathrm{Si}-\mathrm{C}_{2} \mathrm{H}_{4}-\mathrm{Si}\right)$ as a minimum unit forms loose silica networks that are larger than $\equiv \mathrm{Si}-\mathrm{O}$ (TEOS). This concept was proposed as a "spacer technique," and has been confirmed by molecular dynamic simulation (Chang et al., 2010). Thus, it can be concluded that hydrothermally stable organosilica silica, which contains a variety of carbon contents in an amorphous structure, should be a promising membrane material for the practical application of gas and liquid separation. It should be noted that the spacer technique could be combined with the template technique. Lee et al. (2011) applied tetraethoxy-dimethyl disiloxane, which consists of a siloxane linking unit and a methyl group, and successfully controlled pore sizes to within a range of $0.6-1.0 \mathrm{~nm}$. Superior properties and excellent performance of bridged alkoxysilane makes organosilica membranes attractive, and has motivated extensive study.

It is difficult to draw conclusions as to general trends since each factor affects the structure of sols and gels in a complex manner. Obviously, the most crucial factor is the type of precursors that are the linking units between two Si atoms. Figure 7 shows the effect of linking units on gas permeation properties (Kanezashi et al., 2012a). With an increase in the linking unit, permeance increases and permselectivity for $\mathrm{H}_{2} / \mathrm{N}_{2}$ decreases, from more than 100 for TEOS to 10-20 for BTESE membranes, suggesting larger pore sizes. The effect of organic linking units, including linear alkane (flexible) and aromatics (rigid) on temperature dependency, suggests that the flexible bridging units show a higher level of temperature dependence for permeation properties, which is similar to that of polymeric membranes (Castricum et al., 2011; Ren et al., 2014; Kanezashi et al.,

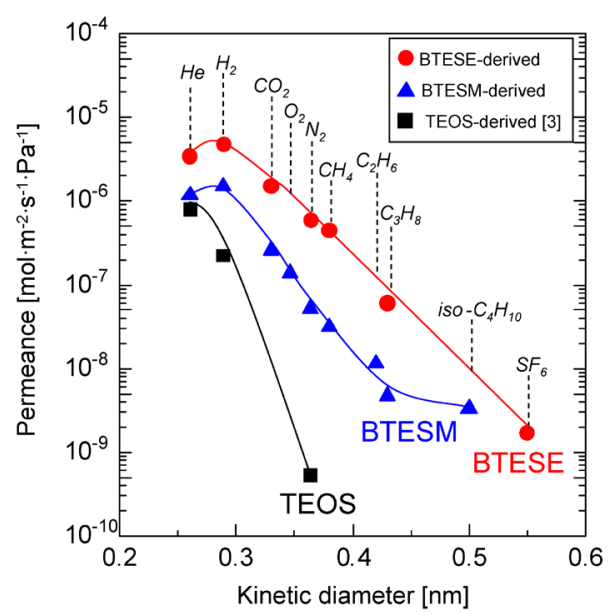

Fig. 7 Effect of precursors on gas permeances of different molecular sizes (Kanezashi et al., 2012a)

2017). Recently, many types of bridged alkoxysilanes have been reported, which include triazine (Ibrahim et al., 2014), pyrimidine (Yu et al., 2017), malonamide (Besselink et al., 2015), and triazole (Yamamoto et al., 2017).

Regarding the effect of sol preparation conditions, Castricum et al. (2015) reported that network pore sizes became dense with a decrease in acid concentration, and combined with the coating under a dried intermediate layer, $\mathrm{H}_{2} / \mathrm{N}_{2}$ selectivity increased several hundred folds. Niimi et al. (2014) reported silica networks become dense with an increase in the water ratio under a constant acid ratio. Sol size is also important in the coating process since small sol sizes allow penetration into the intermediate layer, which results in a thicker coating. A new technique to increase the size of the sol without changing the network pore size involves $\mathrm{pH}$ swing sols where a specific amount of $\mathrm{NH}_{3}$ is added to acid sols that switch to acid after a reaction of several minutes (Yu et al., 2016). The size of BTESE-derived sols that are created using $\mathrm{pH}$-swing are controlled via the $\mathrm{H}_{2} \mathrm{O}$ /BTESE molar ratio and the reaction time in alkali. Under a $\mathrm{H}_{2} \mathrm{O}$ / BTESE ratio of 60 , the BTESE-derived sols prepared using the $\mathrm{pH}$-swing method show an increased sol size that contrasts with that of the acid method, and the sol size is easily controlled via the dominating reaction in alkali $\mathrm{pH}$-the condensation reaction. Gas permeation results have shown that $\mathrm{He}, \mathrm{H}_{2}, \mathrm{~N}_{2}, \mathrm{C}_{3} \mathrm{H}_{8}$, and $\mathrm{SF}_{6}$ permeate $\mathrm{pH}$-swing membranes at approximately twice the speed of acid-sol membranes. Interestingly, it is suggested that the thermal stability of BTESE membranes prepared using $\mathrm{pH}$-swing sols will increase, compared with those of acid-catalyzed sols, due to a higher degree of cross-linking. Doping ions such as Al, Ag, $\mathrm{Nb}$, etc. into organosilica and silica is thought to enhance permselectivity. Qi et al. (2012) reported that $\mathrm{H}_{2} / \mathrm{CO}_{2}$ selectivity was greatly increased due to the formation of a Lewis acid site, which will be introduced later.

Another approach for organosilica is the addition of hydrocarbon into a Si precursor. Duke et al. (2006) added hexyl triethyl ammonium bromide as a cationic surfactant into silica sol, and fired the coated membranes in vacuum. 


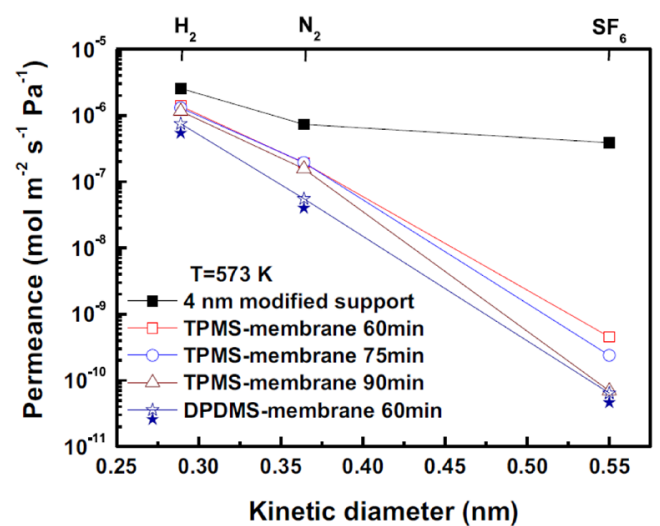

Fig. 8 Gas permeance of TPMS-derived $\mathrm{SiO}_{2}$ membranes prepared for different CVD time (Zhang et al., 2016)

The carbonized-template molecular-sieve silica membranes showed improved hydrothermal stability from the presence of $0.2 \mathrm{wt} \%$ carbon templates in the silica networks, which reduced the movement and/or diffusion of the silanol groups and prevented them from forming densified networks.

1.1.3 Organosilica in CVD When CVD was first reported by Gavalas et al. (1989), porous $\mathrm{SiO}_{2}$ membranes could then be activated for gas separation. As Nomura et al. (2005) reported reproducible production using TMOS in the counter-diffusion mode, most CVD-derived silica membranes have shown a high selectivity to hydrogen over other gases such as $\mathrm{N}_{2}$ and $\mathrm{CO}_{2}$. However, it is rather difficult to fabricate silica membranes with larger pore sizes. Organosilicon compounds containing $\mathrm{Si}-\mathrm{C}$ bonding in the structure were reported using phenyl groups (Ohta et al., 2008; Zhang et al., 2016) or alkyl groups (Nomura et al., 2007, 2014). Nakao group used tetramethoxysilane (TMOS), phenylmtrimethoxysilane (PTMS), diphenyldimethxysilane (DPDMS), and triphenylmethoxysilane (TPMS) in a counter diffusion technique (Ohta et al., 2008; Zhang et al., 2016). A SiO- $\mathrm{CH}_{3}$ bond in methoxide groups reportedly decomposes more easily, and the intermediate of the precursors undergoes oligomerization to form silica networks, which is followed by an oxidation reaction. The resultant pore sizes can be tuned according to the number of bulky phenyl groups. The proposed mechanism is similar to the template technique that is used in sol-gel processing. Figure 8 shows gas permeance as a function of the kinetic diameters for TPMSdeposited membranes together with DPDMS. Following a counter-diffusion CVD time of $10 \mathrm{~min}$, the size dependencies of gas permeance were approximate even after further CVD time, and no change in permeance was observed, indicating that CVD was terminated after formation of the CVD layer in/inside the membranes. TPMS showed a high $\mathrm{H}_{2}$ permeance of $10^{-6} \mathrm{~mol} /\left(\mathrm{m}^{2} \mathrm{~s} \mathrm{~Pa}\right)$ with excellent $\mathrm{H}_{2} / \mathrm{SF}$ selectivity of 12,000 at $573 \mathrm{~K}$.

\subsection{Structural control for the improved performance of silica-based membranes}

As shown in Figure 3, the typical structure of a silica membrane combines a silica top layer with an intermediate layer and support layers. Multi-layered structures require firing processes for each layer, which increases cost, processing time, and requires manual handling. The primary roles of interlayers are to smooth the surface roughness to reduce defects and cracks, which helps prevent the silica sol from penetrating the porous supports. A new concept for an interlayer-free design was proposed by the da Costa group (Liu et al., 2015; Yang et al., 2017). They directly coated an $\alpha$-alumina macroporous substrate with polymeric silica sols mixed with colloidal silica ( $70 \mathrm{~nm}$ in size) sols, and concluded that heterogeneous structures could effectively block and/or repair large pores and defects in supports without interlayers.

Typical intermediate layers are made from $\gamma-\mathrm{Al}_{2} \mathrm{O}_{3}$ or $\mathrm{SiO}_{2}-\mathrm{ZrO}_{2}$, both of which are hydrophilic. In practical operations, such as removing $\mathrm{CO}_{2}$ from flue gases or natural gas, membrane-based gas separations are processed under wet conditions. In the presence of water vapor, water can fill the pores of hydrophilic intermediate layers due to capillary condensation, which can be resistant to gas transport through the membranes. Hydrophobic intermediate layers of several nms, made from methyl- $\mathrm{SiO}_{2} \operatorname{sols}\left(\mathrm{Me}-\mathrm{SiO}_{2}\right)$ prepared via the co-hydrolysis and condensation reaction of methyltrimethoxysilane (MTMS) and TEOS using an alkali catalyst (Tsuru et al., 2011a), have been proposed and successfully applied to $\mathrm{CO}_{2}$ permeation under wet conditions (Ren et al., 2015).

A completely different approach involves the use of polymeric nanoporous membranes for deposition of the silica top layer. Ngamou et al. (2013) successfully deposited a BTESE-derived silica layer onto porous polyamide-imide substrates via an expanding thermal plasma chemical vapor deposition (ETP-CVD) approach. Unfortunately, the carbon bridges were oxidized by the abundant reactive oxygen species due to a thermally enhanced oxidation reaction during plasma deposition. Reportedly, approximately 30\% of the $\mathrm{Si}-\mathrm{C}-\mathrm{C}-\mathrm{Si}$ bridges were retained in the BTESE networks, which resulted in the separation of pure BTESE and pure $\mathrm{SiO}_{2}$. On the other hand, Gong et al. (2014) proposed a facile sol-gel coating process where a thin and uniform BTESE-derived silica layer was successfully deposited onto a porous polysulfone support, and successfully prepared the layered hybrid membrane with a stable water flux of $2.3 \mathrm{~kg} /\left(\mathrm{m}^{2} \mathrm{~h}\right)$ and a separation factor of approximately 2,500 for the dehydration of IPA/water (IPA: $90 \mathrm{wt} \%$ ) solutions at $105^{\circ} \mathrm{C}$ during vapor permeation (VP).

\subsection{Processing for the improved performance of silica- based membranes}

The effect of firing temperature was examined for MTES and TEOS-derived membranes. Higher firing temperatures densified the silica networks due to the increased condensation of silanol groups (de Vos et al., 1999), which increased the hydrothermal stability (Kanezashi et al., 2014). When firing organosilica at higher temperatures, densification and decomposition of organic groups occurs simultaneously, which leads to a complicated process but allows additional 


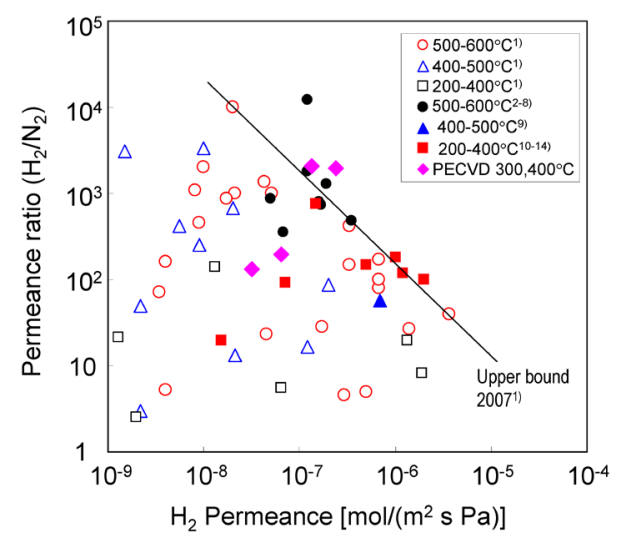

Fig. 9 Selectivity $\left(\mathrm{H}_{2} / \mathrm{N}_{2}\right)$ as a function of $\mathrm{H}_{2}$ permeance for silica membranes (Tsuru et al., 2011b).

control of pore-size distribution (Lee et al., 2011).

Plasma-enhanced chemical vapor deposition (PECVD) is commonly used to prepare thin films, and has been utilized in preparing silica membranes. Highly permselective organosilica membranes were deposited onto porous ceramic supports using hexamethyldisiloxane (HMDSO) as a precursor via a newly developed two-step PECVD technique, which involved deposition in Ar plasma, and subsequently in $\mathrm{O}_{2}$ plasma for high performance, as shown in Figure 9 (Tsuru et al., 2011b). Recently, atmosphericpressure PECVD (AP-PECVD) was first applied to the fabrication of silica membranes for gas separation (Nagasawa et al., 2017). HMDSO was selected as a silicon precursor, and was fed into an afterglow region of atmospheric-pressure plasma to deposit a silica layer onto a porous support. As-deposited membranes showed He permeance of $1.1 \times 10^{-7} \mathrm{~mol} /\left(\mathrm{m}^{2} \mathrm{~s} \mathrm{~Pa}\right)$ and a $\mathrm{He} / \mathrm{N}_{2}$ permeance ratio of 196 , and after annealed at $300^{\circ} \mathrm{C}$, showed a similar performance with increased $\mathrm{CO}_{2}$ selectivity $\left(\mathrm{CO}_{2} / \mathrm{CH}_{4}=166\right)$, which suggested the formation of pores that would be effective for $\mathrm{CO}_{2}$ permeation.

Interfacial polymerization of octa-ammonium POSS (polyhedral oligomeric silsesquioxane) in water and 6-FDA (hexafluoroisopropylidene dianhydride) in toluene was proposed for the production of hyper-cross-linked hybrid membranes (Raaijmakers et al., 2014). The reaction occurred at the water/toluene interface, with the final polyPOSS-(amic acid) thicknesses of $\sim 0.1 \mu \mathrm{m}$ following a reaction time of $5 \mathrm{~min}$, followed by conversion of the amic acid to cyclic imide (imidization) via heat treatment at temperatures as high as $300^{\circ} \mathrm{C}$. Interfacial polymerization, which is commonly used for large-scale defect-free processing of polyamide desalination membranes, is of great interest and promising for the facile production of defect-free thin-film organosilica membranes.

\section{Application}

Separation membranes are usually evaluated based on (1) selectivity, (2) permeability, and, from a practical point of view, (3) chemical and thermal stability under operating
Table 2 Typical applications of silica-based membranes

\begin{tabular}{|c|c|}
\hline Separation systems & Applications \\
\hline \multicolumn{2}{|l|}{ 1. Gas } \\
\hline$-\mathrm{H}_{2} / \mathrm{N}_{2}, \mathrm{H}_{2} /$ hydrocarbon & $-\mathrm{H}_{2}$ recovery, purification \\
\hline$-\mathrm{CO}_{2} / \mathrm{CH}_{4}, \mathrm{CO}_{2} / \mathrm{N}_{2}$ & $\begin{array}{l}-\mathrm{CH}_{4} \text { from bio- and natural gas, } \\
\mathrm{CO}_{2} \text { recovery for CCS }\end{array}$ \\
\hline -Organic gas (C3"/C3) & $\begin{array}{l}\text {-Olefin/paraffin separation in } \\
\text { petrochemical industries }\end{array}$ \\
\hline \multicolumn{2}{|l|}{ 2. Vapor/Pervaporation } \\
\hline $\begin{array}{l}-\mathrm{H}_{2} \mathrm{O} / \text { alcohol (EtOH, IPA), } \\
\mathrm{H}_{2} \mathrm{O} / \text { acetic acid, }\end{array}$ & $\begin{array}{l}\text {-Dehydration of organics such as } \\
\text { alcohols forming azeotropes }\end{array}$ \\
\hline -Concentration of organics & $\begin{array}{l}\text {-Selective permeation of organics } \\
\text { over water }\end{array}$ \\
\hline \multicolumn{2}{|l|}{ 3. Reverse osmosis } \\
\hline$-\mathrm{H}_{2} \mathrm{O} / \mathrm{NaCl}$ & $\begin{array}{l}\text {-Water purification under harsh } \\
\text { conditions such as high tem- } \\
\text { peratures }\end{array}$ \\
\hline \multicolumn{2}{|l|}{ 4. Membrane reactor } \\
\hline - $\mathrm{MCH}$ and $\mathrm{HI}$ dehydrogenation & $\begin{array}{l}\text {-Hydrogen production from } \\
200-300^{\circ} \mathrm{C} \text {. }\end{array}$ \\
\hline
\end{tabular}

conditions over a long period, which is closely related to the lifetime of a membrane. In addition, the cost of membranes and modules is the most critical point in the replacement of conventional separation processes for practical applications. Economical simulation has suggested that increasing the level of permeance is more important than that of selectivity once a certain level of selectivity has been reached (Merkel et al., 2012; Lin et al., 2015).

In this section, promising applications of organosilica membranes are summarized in Table 2. As much as possible, the information in Table 2 refers to trade-off curves, which correlate selectivity and permeance. Some of the trade-off curves are not updated, but remain useful in explaining state-of-art membrane performance for specific separation systems.

\subsection{Gas separation}

Although organosilica membranes have been commercialized for the dehydration of organic aqueous solutions (van Veen et al., 2011; Agirre et al., 2014), gas separation also shows promise. Since typical organosilica membranes have large pores, as mentioned, hydrogen separation from large-sized molecules has potential applications. Figure $\mathbf{1 0}$ shows the selectivity for $\mathrm{H}_{2} / \mathrm{SF}_{6}$ of a BTESE-derived organosilica membrane as a function of $\mathrm{H}_{2}$ permeance; $\mathrm{SF}_{6}$, $0.55 \mathrm{~nm}$ in size, is one of the largest gases, and is often used as a standard for pore size distribution. Organosilica membranes have clearly shown $\mathrm{H}_{2}$ permeance higher than $10^{-6} \mathrm{~mol} /\left(\mathrm{m}^{2} \mathrm{~s} \mathrm{~Pa}\right)$ with $\mathrm{H}_{2} / \mathrm{SF}_{6}$ permeance ratios as high as 1,000 , compared with zeolite and carbon membranes, probably due to the thin-film formation of a smaller number of large pores such as pinholes (Kanezashi et al., 2009). Recently, although the primary factors affecting gas separation performance are the linking units, BTESE-derived membranes showed $\mathrm{H}_{2} / \mathrm{N}_{2}$ selectivity that ranged from $50-400$ by decreasing both acid and water ratios, which reportedly en- 


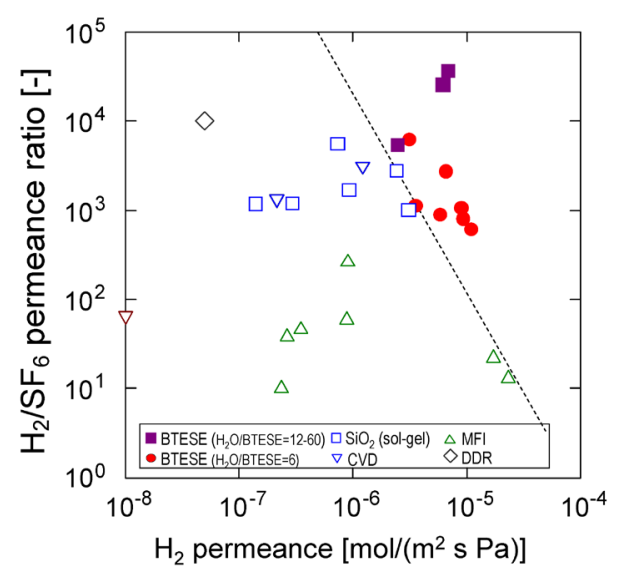

Fig. 10 Trade-offs for $\mathrm{H}_{2} / \mathrm{SF}_{6}$ for organosilica and zeolite membranes at $200^{\circ} \mathrm{C}$ and $25^{\circ} \mathrm{C}$. (Kanezashi et al., 2009)
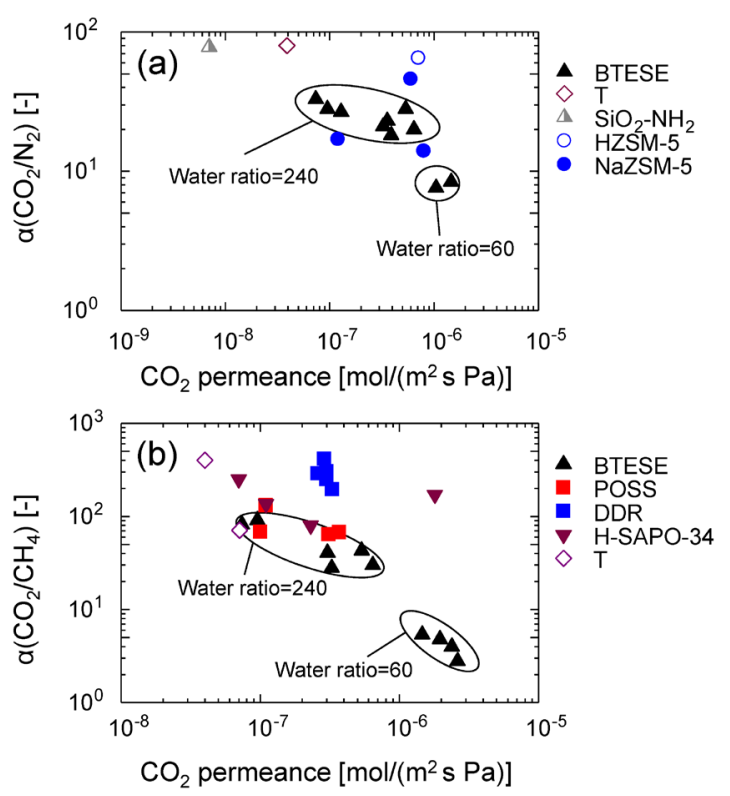

Fig. 11 Trade-offs for $\mathrm{CO}_{2} / \mathrm{N}_{2}$ and $\mathrm{CO}_{2} / \mathrm{CH}_{4}$. (Yu et al., 2016)

hanced the densification of silica networks (Castricum et al., 2015). This result is clear evidence of the controllability of a wide range of pore networks in organosilica membranes.

$\mathrm{CO}_{2}$ separation is another important application, and includes $\mathrm{CO}_{2}$ removal from natural gas and flue gases. Figure 11 shows the trade-offs for $\mathrm{CO}_{2} / \mathrm{N}_{2}$ and $\mathrm{CO}_{2} / \mathrm{CH}_{4}$ for BTESE-derived organosilica and zeolite (DDR, SAPO) membranes. DDR and SAPO-34 showed high permeance ratios $(>100)$ for $\mathrm{CO}_{2} / \mathrm{CH}_{4}$, while BTESE-derived membranes showed the highest selectivity of 90 and $\mathrm{CO}_{2}$ permeance of $1 \times 10^{-7}-2.6 \times 10^{-6} \mathrm{~mol} /\left(\mathrm{m}^{2} \mathrm{~s} \mathrm{~Pa}\right)$. BTESE-derived membranes demonstrated a moderate level of selectivity and a wide range of $\mathrm{CO}_{2}$ permeance for both $\mathrm{CO}_{2} / \mathrm{N}_{2}$ and $\mathrm{CO}_{2} / \mathrm{CH}_{4}$ (Yu et al., 2016). Qi et al. (2012) reported that $\mathrm{H}_{2} / \mathrm{CO}_{2}$ permselectivity was largely increased due to the formation of Lewis acid sites. In addition, Nb-doped BTESE showed excellent stability in the presence of $150 \mathrm{kPa}$ steam at temperatures under $200^{\circ} \mathrm{C}$, as evidenced by steady $\mathrm{H}_{2}$

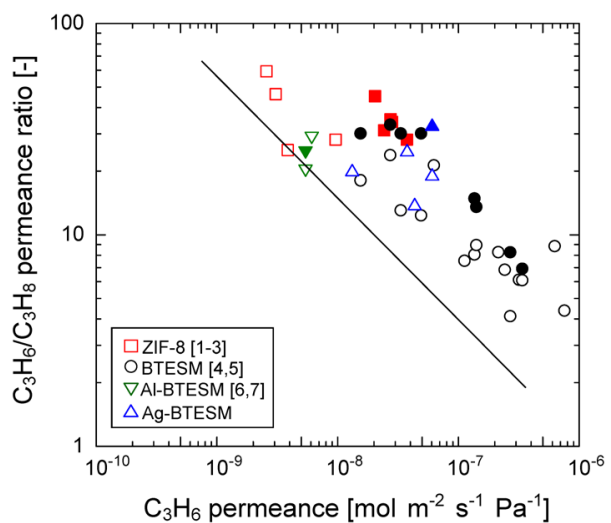

Fig. $12 \mathrm{C}_{3} \mathrm{H}_{6} / \mathrm{C}_{3} \mathrm{H}_{8}$ as a function of $\mathrm{C}_{3} \mathrm{H}_{6}$ permeance at $22-50^{\circ} \mathrm{C}$ for carbon, zeolite, and organosilica membranes (Kanezashi et al., 2012b)

permeance and excellent $\mathrm{H}_{2} / \mathrm{CO}_{2}$ permselectivities as high as 700 during long-term stability testing for as long as $300 \mathrm{~h}$. The highest selectivity of $\mathrm{H}_{2}$ over $\mathrm{CO}_{2}$ was more than 1,000. The mechanism, however, remains in question (ten Elshof and Dra, 2016). Alkylamine-silica membranes with a pendant-type structure were prepared at $673 \mathrm{~K}$ via CVD using 3-aminopropyltrimethoxysilane and (3-methyaminopropyl) trimethoxysilane as primary and secondary alkylamine-silica precursors, respectively. The secondary amine precursor showed the most promising performance among the amine-based and non-amine silica membranes, although XPS revealed that N/Si ratios were 0.03 due to pyrolysis of the amine groups (Messaoud et al., 2015). Finally, a new strategy for improving $\mathrm{CO}_{2}$ selectivity was proposed by fluorine doping into $\mathrm{SiO}_{2}$ networks, although, at present, it has not yet been applied to organosilica. Fluorine, which was doped as ammonium fluoride into TEOS-derived solutions, reportedly tuned the pore sizes to a looser and more uniform state than without doping, which resulted in the successful preparation of fluorine-dope silica membranes with high $\mathrm{CO}_{2}$ permeance $\left(4 \times 10^{-7} \mathrm{~mol} /\left(\mathrm{m}^{2} \mathrm{sPa}\right)\right)$ and excellent $\mathrm{CO}_{2} / \mathrm{CH}_{4}$ selectivity ( $\gg 300$ ) (Kanezashi et al., 2016).

Separation of olefin from paraffin is of great interest for future applications. Currently, propylene/propane is usually separated by distillation columns of more than 100 stages with a high reflux ratio, which requires a large amount of energy consumption. Various types of membranes, including polymer, carbon, zeolite, MOF, and silica, have been explored for this important separation. As shown in Figure 12, a zeolitic imidazolate framework (ZIF-8) showed excellent selectivity $(\sim 45)$ that exceeded the upper bounds (solid line in the figure, based on carbon membranes). On the other hand, BTESM-derived organosilica showed a higher level of permeance and moderate-to-similar selectivity. Precise control of the silica networks by the bridged alkoxysilanes resulted in the attainment of a high separation factor (Kanezashi et al., 2012b). In addition, metal (Al, Ag) doping was examined for the possibility that it could increase the separation performance. 


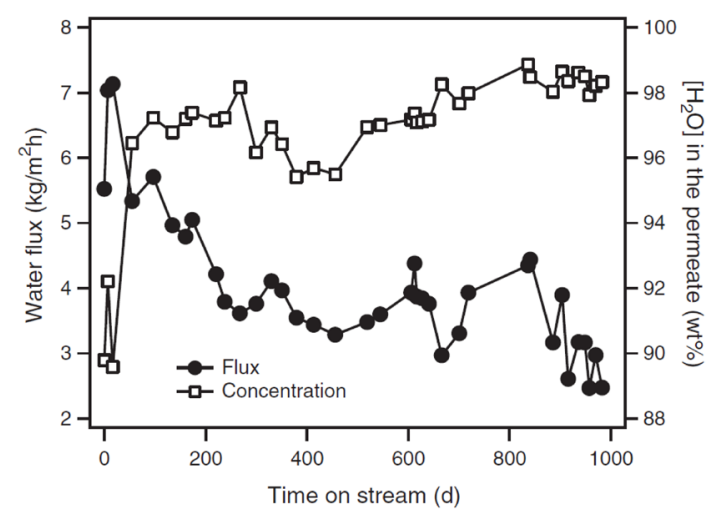

Fig. 13 Long-term separation for BTESE-derived membrane for $\mathrm{H}_{2} \mathrm{O} / \mathrm{BuOH}\left(\mathrm{H}_{2} \mathrm{O}: 5 \mathrm{wt} \%\right)$ at $150^{\circ} \mathrm{C}$. (van Veen et al., 2011)

Table 3 PV dehydration performance of alcohol aqueous solutions (5 wt $\%$ water)

\begin{tabular}{lccc}
\hline \multirow{2}{*}{ Alcohols } & $T\left[{ }^{\circ} \mathrm{C}\right]$ & \multicolumn{2}{c}{ Water concentration in permeate } \\
\cline { 3 - 4 } & & BTESE & BTESM \\
\hline$n-\mathrm{BuOH}$ & 95 & 99.6 & 99.8 \\
$n-\mathrm{PrOH}$ & 85 & 99.5 & 99.5 \\
$\mathrm{EtOH}$ & 70 & 89.2 & 92.2 \\
$\mathrm{MeOH}$ & 55 & 18.6 & 55.1 \\
\hline
\end{tabular}

\subsection{Pervaporation(PV)/vapor-permeation(VP)}

Castricum et al. (2008a, 2008b) successfully prepared pure BTESE membranes for the dehydration of aqueous butanol solutions, and found that BTESE membranes showed a superior separation factor that reached as high as several thousands. More importantly, the BTESE membranes showed high stability at $150^{\circ} \mathrm{C}$ for as many as $500 \mathrm{~d}$ without a decline in selectivity, and with only a gradual decrease in flux (Figure 13) (van Veen et al., 2011). Table 3 summarizes the PV dehydration of BTESE and BTESM-derived membranes for water/alcohol mixtures (Agirre et al., 2014). BTESM showed higher selectivity than BTESE due to smaller pore sizes and higher selectivity for alcohols with higher carbon numbers. Both membranes showed excellent selectivity that was better than that of BTESE-MTES copolymerized membranes, which suggested the importance of connectivity in silica networks.

Figures 14 and 15 show the trade-offs between the separation factor and the permeance of water for the dehydration of isopropanol (Wang et al.. 2013) and acetic acid aqueous solutions (Tsuru et al., 2012) $\left(75^{\circ} \mathrm{C}\right.$, water concentration: $10 \mathrm{wt} \%)$, respectively. Generally speaking, organosilica and pure silica membranes show a high level of permeance and moderate separation factors, while zeolite membranes show high separation factors with moderate permeance. Polymeric membranes show comparatively low permeance and separation factors. BTESEderived organosilica membranes show a water permeance of $(2-5) \times 10^{-6} \mathrm{~mol} /\left(\mathrm{m}^{2} \mathrm{~s} \mathrm{~Pa}\right)$ for $90 \mathrm{wt} \% \mathrm{AcOH}$, corresponding to $2.0-4.0 \mathrm{~kg} /\left(\mathrm{m}^{2} \mathrm{~h}\right)$, and moderate separation factors that

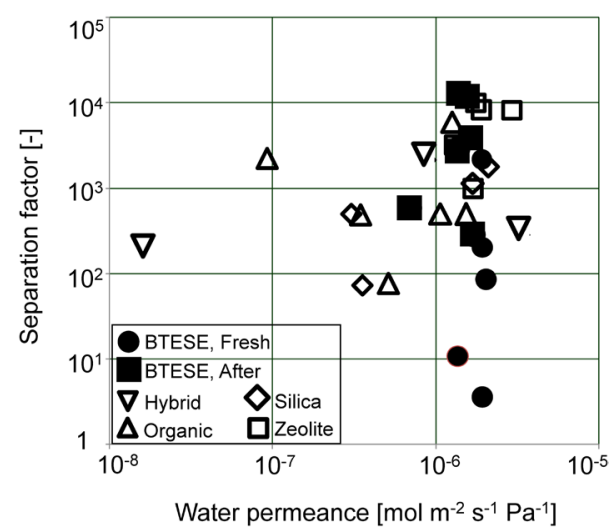

Fig. 14 Trade-offs for PV dehydration of water/IPA (water: 10wt\%, $75^{\circ} \mathrm{C}$ ) (Wang et al., 2013)

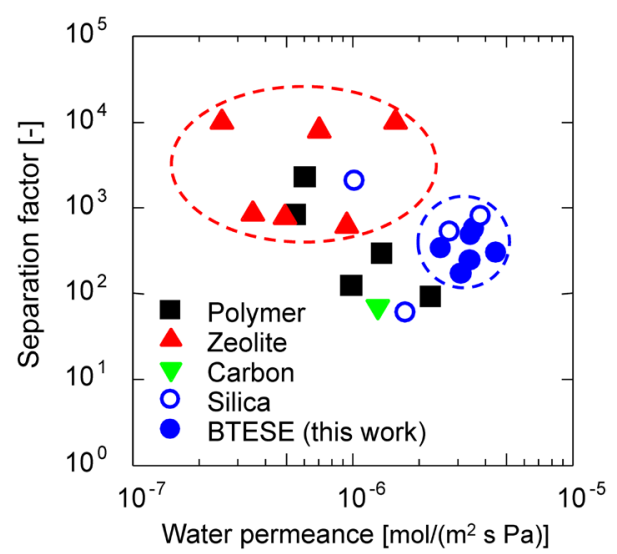

Fig. 15 Trade-offs for PV dehydration of water/acetic acid (water: $10 \mathrm{wt} \%$ ) (Tsuru et al., 2012)

range from 200-500. Long-term $(1,800 \mathrm{~h})$ immersion testing in $90 \mathrm{wt} \%$ acetic acid at room temperature confirmed the stability of organosilica membranes. On the other hand, stronger acids, such as $\mathrm{HNO}_{3}$, are known to damage BTESE membranes. Since BTESE was reported to be stable in acid, $\gamma-\mathrm{Al}_{2} \mathrm{O}_{3}$ intermediate layers could have caused the possible damage (Castricum et al., 2008c). In another PV dehydration system, stable performance was reported for $N$-methyl pyrrolidone (NMP) aqueous solutions (van Veen et al., 2011).

The applications mentioned above focused on the dehydration of organic aqueous solutions based on the selective removal of water via a molecular-sieving mechanism. Another interesting application of organosilica membranes is the selective removal of organic compounds. Paradis et al. (2013) prepared a BTESE-RTES ( $\mathrm{R}=$ alkyl group including methyl, propyl, hexyl and decyl) membrane and found that permselectivity was changed from water-selective to butanol-selective when the carbon number increased. Araki et al. (2016) prepared hydrophobic silica membranes using a series of pendant type alkoxysilanes, including alkoxysilanes, ethyltrimethoxysilane (ETMS), n-propyltrimethoxysilane (PrTMS), isobutyltrimethoxysilane (BTMS), hexyltrimethoxysilane (HTMS), and phenyltrimethoxysilane 
(PhTMS), to remove a concentration of ethyl acetate from water. All of the organosilica membranes had pore sizes that ranged from $1.0-1.3 \mathrm{~nm}$, and the BTMS membrane had the largest selectivity of all membranes due to the affinity between the membranes and the organic compound.

PV desalination was reported by the da Costa group. Interlayer-free hybrid carbon-silica membranes prepared from TEOS, triethoxyvinylsilane (TEVS) and non-ionic pluronic triblock copolymer (P123) showed a high water flux with high salt rejection (more than 99\%) (Yang et al., 2017).

\subsection{Reverse osmosis (R0)}

Reverse osmosis ( $\mathrm{RO}$ ) is the most commonly used technology for water purification, and is used in a variety of applications. Polyamide thin-film composite (TFC) RO membranes currently dominate the commercial market. However, polyamide TFC membranes are quite susceptible to chlorine, which is the most widely used disinfectant in water treatment for biofouling control. The organosilica membranes derived from BTESE exhibited superior molecular sieving ability for neutral solutes of low molecular weight, showing molecular weight cut-offs of approximately 60-100, and a level of conventional seawater desalination that approximated that of RO membranes. More importantly, the organosilica membranes showed not only exceptional hydrothermal stability, but also excellent stability under chlorine exposure of more than $35,000 \mathrm{ppm}$ h. Figure $\mathbf{1 6}$ illustrates the trade-off in terms of $\mathrm{NaCl}$ rejection and water permeability (Ibrahim et al., 2015). Compared with conventional polyamide TFC membranes, water permeance values for BTESE-derived organosilica membranes are one to two orders of magnitude lower, probably because the organosilica membranes have more rigid and hydrophobic micropores (Ibrahim et al., 2015), and PA membranes have a thin separation layer $(\sim 20 \mathrm{~nm})$ with high surface area ascribed to the surface ridge-and valley structure (Kong et al., 2010).

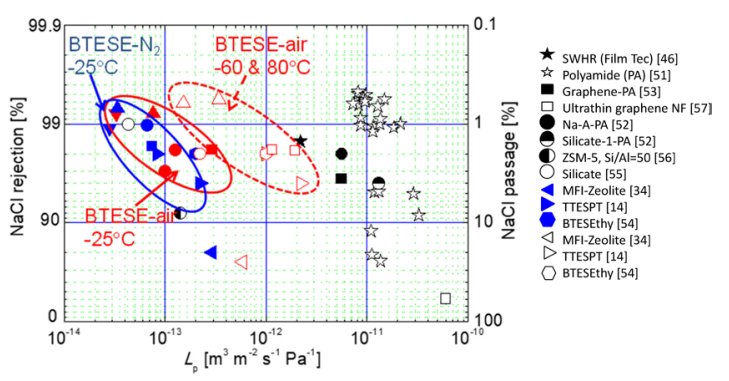

Fig. $16 \mathrm{NaCl}$ rejection and water permeability for RO desalination (Ibrahim et al., 2015)
Therefore, extensive work has been dedicated to improving water permeability. Since the organosilica is hydrothermally stable, a more interesting application will include $\mathrm{RO}$ at high temperatures that polymeric membranes cannot typically withstand.

\subsection{Membrane reactor}

Another important application of organosilica membranes is the use of membrane reactors for hydrogen production. A membrane reactor that combines a catalytic reaction and separation in one unit can shift the equilibrium and purify hydrogen as a result of the selective hydrogen extraction, resulting in enhanced conversion in reactor/separation units of smaller size and/or reduced reaction temperatures. Typical reactions, as summarized in Table 4, include stream reforming methane $\left(500-600^{\circ} \mathrm{C}\right.$, under steam), $\mathrm{NH}_{3}$ decomposition $\left(400-500^{\circ} \mathrm{C}\right.$, without steam), and organic hydrides such as methylcyclohexane (MCH)/toluene (T) (Meng et al., 2015). Dehydrogenation of organic hydrides, which requires relatively low temperatures $\left(250-300^{\circ} \mathrm{C}\right)$ under dry conditions, could make organosilica membranes more feasible than palladium-based membranes, which have shown decreased permeance and suffer from instability at low temperatures. In addition, a larger difference in the molecular size between hydrogen and organic components allows microporous membranes with high selectivity for hydrogen over other gases to be alternative materials for hydrogen production. $\mathrm{MCH}$ conversion was increased to $75 \%$, which was higher than the equilibrium conversion of $60 \%$, with hydrogen purity in the permeate stream of more than $99.9 \%$ at $230^{\circ} \mathrm{C}$ (Niimi et al., 2014; Meng et al., 2015). Membrane reactor operation longer than $1,000 \mathrm{~h}$ confirmed the stability of organosilica membranes CVD-derived from DMDPS (Akamatsu et al., 2015).

Another new application of a membrane reactor, hydrogen purification during a hydrogen iodine decomposition reaction, has been proposed and examined using CVD silica membranes derived from hexylmethoxysilane (Myagmarjav et al., 2017).

\section{Transport Model}

The permeation mechanism of gases through nonporous membranes is well described with the following solutiondiffusion (SD) model (Adams et al., 2017)

$$
P^{*}=P_{0}^{*} \exp \left(\frac{-E_{p}}{R T}\right)=P_{0}^{*} \exp \left(\frac{-E_{D}-H_{s}}{R T}\right)
$$

Table 4 Hydrogen production in membrane reactors

\begin{tabular}{lccc}
\hline \multicolumn{1}{c}{ Reaction system } & Temperature $\left[{ }^{\circ} \mathrm{C}\right]$ & Dry/steamed & Permeate/retentate \\
\hline Steam reforming of methane & $500-600$ & Hydro-thermal & $\mathrm{H}_{2} / \mathrm{CH}_{4}, \mathrm{CO}_{2}, \mathrm{CO}_{2}, \mathrm{H}_{2} \mathrm{O}$ \\
$\mathrm{NH}_{3}$ decomposition & $400-500$ & Dry & $\mathrm{H}_{2} / \mathrm{NH}_{3}, \mathrm{~N}_{2}$ \\
Methylcyclohexane $(\mathrm{MCH})$ dehydrogenation & $200-300$ & Dry & $\mathrm{H}_{2} /$ toluene, $\mathrm{MCH}$ \\
\hline
\end{tabular}


Here, $P_{0}^{*}$ is the pre-exponential factors, $E_{p}$ and $E_{D}$ are the apparent activation energies for permeation and diffusion, respectively, and $\Delta H_{s}$ is the effective sorption enthalpy.

On the other hand, porous membranes can be categorized as viscous flow (molecular diffusion), Knudsen, surface diffusion, and molecular sieving, depending on the structures (molecular size and shape, pore size), the interaction between permeating molecules and membrane pore walls, and the operating conditions (pressure, temperature). For gas separation through subnano-meter levels, the modified gas translation model (mGT) was recently proposed by considering the effective diffusion distance $\left(d_{p}-d_{i}\right)$ of the $i$-th component in the original GT equation. The permeance, $P_{i}$, through a membrane (pore diameter, $d_{\mathrm{p}}$; porosity, $\varepsilon$; tortuosity, $\tau$, thickness, $L$ ) is formulated as follows (Lee et al., 2011).

$$
\begin{aligned}
P_{i} & =\varepsilon\left(d_{p}-d_{i}\right) \frac{\left(d_{p}-d_{i}\right)^{2}}{3 d_{p}^{2}} \sqrt{\frac{8 R T}{\pi M_{i}}} \frac{1}{R T \tau L} \exp \left(-\frac{E_{p, i}}{R T}\right) \\
& =\frac{k_{0, i}}{\sqrt{M_{i} R T}} \exp \left(-\frac{E_{p, i}}{R T}\right)
\end{aligned}
$$

Here, $M_{i}$ and $E p, i$, are the molecular weight and the kinetic energy of the $i$-th component, respectively; $R$ is the universal gas constant, and $T$ is the absolute temperature.

Based on Eq. (2), normalized Knudsen-based permeance (NKP), $f$, that is, the permeance ratio of the $i$-th component to that predicted from He based on the Knudsen diffusion mechanism, can be analyzed as follows, under the assumption of a negligible difference in the kinetic energy of permeation.

$$
\mathrm{f}=\frac{P_{i}}{P_{\mathrm{He}} \sqrt{M_{\mathrm{He}} / M_{i}}}=\frac{\left(1-d_{i} / d_{p}\right)^{3}}{\left(1-d_{\mathrm{He}} / d_{p}\right)^{3}}
$$

For a more precise analysis, the mGT model was further extended by considering the activation energy of each gas component (Yoshioka et al., 2013).

The concept of NKP was verified using the permeance data of MFI and DDR zeolite membranes consisting of intrinsic pore sizes. It was applied to the quantitative evaluation of amorphous silica membranes (Lee et al., 2011). Figure 17 (top) shows how NKP could be applied for the analysis of pore sizes. The NKP values for each gas were best-fitted to obtain pore size, $d_{\mathrm{p}}$, of $0.34,0.52$, and $0.76 \mathrm{~nm}$ for TEOS, MTES and PhTES membranes, respectively. With an increase in pore size, TEOS and BTESE-derived silica membranes showed increased permeance. MTES and PhTES-derived membranes showed relatively large pore sizes, but the $\mathrm{H}_{2}$ permeances were more than one order lower than those of TEOS and BTESE membranes. This was probably because the effective pore space of the silica matrix available for gas permeation was decreased due to space occupation by the pendant groups (Li et al., 2011). In this way, the mGT model would be useful to quantitatively discuss the pore sizes at a subnano-meter level, along with the permeation properties.

Another point that should be addressed is the applicabil-
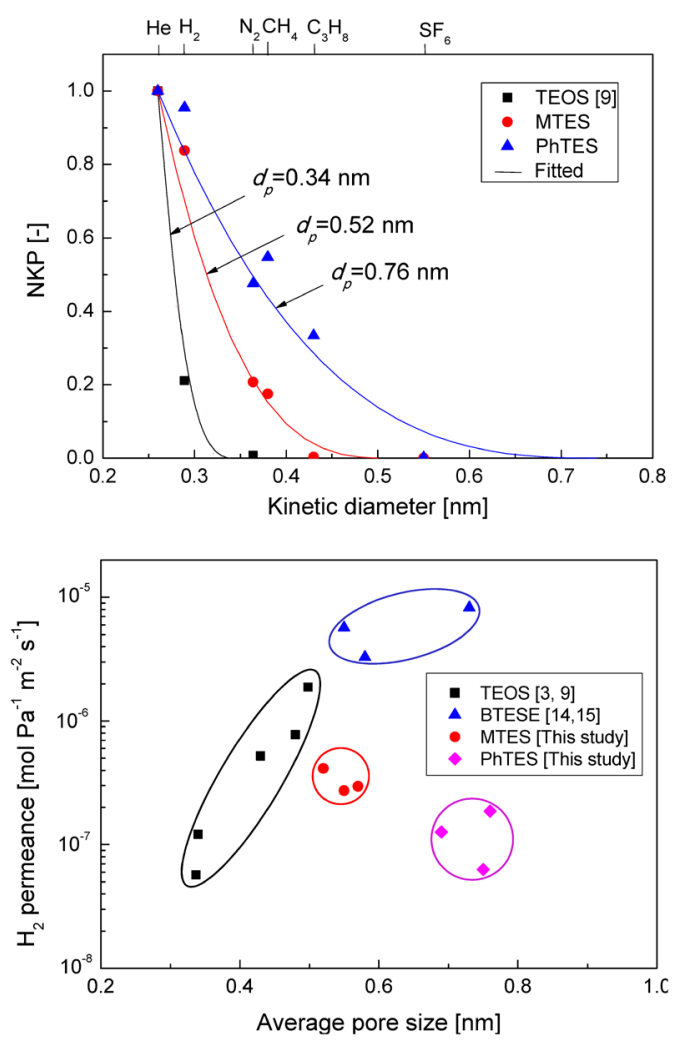

Fig. 17 Top: Normalized Knudsen-based curves for TEOS, MTES, PhTES membranes (curves are fitted using Eq. 2), Bottom: $\mathrm{H}_{2}$ permeance as a function of average pore sizes (Li et al., 2011)

ity of the two models (SD and mGT). The mGT model was originally derived under an assumption of cylindrical and rigid pores, while nonporous structures, typically a dense polymer, were assumed for the solution-diffusion model. When the pore sizes became smaller at the subnano-meter level, the difference between the two models was unclear. In fact, Koros and co-authors applied the SD model to microporous silica membranes prepared by pyrolyzing silanol-terminated PDMS/TEOS-derived films under oxygen at $377^{\circ} \mathrm{C}$ (Adams et al., 2017). As pointed out previously, organosilica is actually a hybrid at the molecular level with a structure that lies somewhere between a flexible polymer and a rigid siloxane. Examples of organosilica with a higher ratio of carbon/silicon $(\mathrm{C} / \mathrm{Si})$ are reported to show a higher level of activated energy for permeation (Castricum et al., 2011; Ren et al., 2014; Kanezashi et al., 2017). An understanding of the transport mechanism through subnano-porous membranes is integral to understanding and predicting permeation properties such as the effects of molecular size, pore size, and temperature dependency from theoretical and practical viewpoints, all of which impact the design of highperformance membranes.

\section{Conclusions}

This review outlined the current status of silica-based membranes in terms of preparation, application and characterization. Recent progress in the fabrication of mem- 
branes was discussed following the general categorization of materials, structural control, and processing. Regarding materials, organosilica membranes, including pendant and bridged types, have made great progress in the past decade. Organosilica membranes were successfully prepared by solgel processing and CVD technique, and show great potential in gas and liquid phase separation. In particular, bridged alkoxysilane, which was first reported in 2008 using bistriethoxysilylethane (BTESE), has ushered in a new stage for silica membranes. A great variety of organosilica can be developed using different types of precursors. Further study on the control and processing of silica networks, together with characterization, will facilitate future industrial applications.

\section{Acknowledgement}

This work was supported by the Japan Society for the Promotion of Science (JSPS) KAKENHI Grant Number 15H02313 and 18H03855.

\section{Literature Cited}

Adams, J., N. Bighane and W. J. Koros; "Pore Morphology and Temperature Dependence of Gas Transport Properties of Silica Membranes Derived from Oxidative Thermolysis of Polydimethylsiloxane," J. Membr. Sci., 524, 585-595 (2017)

Agirre, I., P. L. Arias, H. L. Castricum, M. Creatore, J. E. ten Elshof, G. G. Paradis, P. H. T. Ngamou, H. M. van Veen and J. F. Vente; "Hybrid Organosilica Membranes and Processes: Status and Outlook," Separ. Purif. Technol., 121, 2-12 (2014)

Ahn, S. J., A. Takagaki, T. Sugawara, R. Kikuchi and S. T. Oyama; "Permeation Properties of Silica-Zirconia Composite Membranes Supported on Porous Alumina Substrates," J. Membr. Sci., 526, 409-416 (2017)

Akamatsu, K., T. Tago, M. Seshimo and S. Nakao; "Long-Term Stable $\mathrm{H}_{2}$ Production from Methylcyclohexane Using a Membrane Reactor with a Dimethoxydiphenylsilane-Derived Silica Membrane Prepared via Chemical Vapor Deposition," Ind. Eng. Chem. Res., 54, 3996-4000 (2015)

Araki, S., D. Gondo, S. Imasaka and H. Yamamoto; "Permeation Properties of Organic Compounds from Aqueous Solutions through Hydrophobic Silica Membranes with Different Functional Groups by Pervaporation," J. Membr. Sci., 514, 458-466 (2016)

Asaeda, M., J. Yang and Y. Sakou; "Porous Silica-Zirconia (50\%) Membranes for Pervaporation of iso-Propyl Alcohol (IPA)/Water Mixtures," J. Chem. Eng. Japan, 35, 365-371 (2002)

Besselink, R., H. Qureshi, L. Winnubst and J. E. ten Elshof; "A Novel Malonamide Bridged Silsesquioxane Precursor for Enhanced Dispersion of Transition Metal Ions in Hybrid Silica Membranes," Microporous Mesoporous Mater., 214, 45-53 (2015)

Castricum, H. L., A. Sah, R. Kreiter, D. H. A. Blank, J. F. Vente and J. E. ten Elshof; "Hybrid Ceramic Nanosieves: Stabilizing Nanopores with Organic Links," Chem. Commun. (Camb.), 9, 1103-1105 (2008a)

Castricum, H. L., A. Sah, R. Kreiter, D. H. A. Blank, J. F. Vente and J. E. ten Elshof; "Hydrothermally Stable Molecular Separation Membranes from Organically Linked Silica," J. Mater. Chem., 18, 2150-2158 (2008b)

Castricum, H. L., R. Kreiter, H. D. van Veen, D. H. A. Blank, J. F. Vente and J. E. ten Elshof; "High-Performance Hybrid Pervaporation Membranes with Superior Hydrothermal and Acid Stability," J. Membr. Sci., 324, 111-118 (2008c)
Castricum, H. L., G. G. Paradis, M. C. Mittelmeijer-Hazeleger, R. Kreiter, J. F. Vente and J. E. ten Elshof; "Tailoring the Separation Behavior of Hybrid Organosilica Membranes by Adjusting the Structure of the Organic Bridging Group," Adv. Funct. Mater., 21, 2319-2329 (2011)

Castricum, H. L., H. F. Qureshi, A. Nijmeijer and L. Winnubst; "Hybrid Silica Membranes with Enhanced Hydrogen and $\mathrm{CO}_{2}$ Separation Properties," J. Membr. Sci., 488, 121-128 (2015)

Chang, K., T. Yoshioka, M. Kanezashi, T. Tsuru and K. Tung; "A Molecular Dynamics Simulation of a Homogeneous OrganicInorganic Hybrid Silica Membrane," Chem. Commun. (Camb.), 46, 9140-9142 (2010)

de Vos, R. M., W. F. Maier and H. Verweij; "Hydrophobic Silica Membranes for Gas Separation,” J. Membr. Sci., 158, 277-288 (1999)

Duke, M. C., J. C. D. da Costa, D. D. Do, P. G. Gray and G. Q. Lu; "Hydrothermally Robust Molecular Sieve Silica for Wet Gas Separation," Adv. Funct. Mater., 16, 1215-1220 (2006)

Gavalas, G. R., C. E. Megiris and S. W. Nam; "Deposition of $\mathrm{H}_{2}$-Permselective $\mathrm{Sio}_{2}$ Films," Chem. Eng. Sci., 44, 1829-1835 (1989)

Gong, G., J. Wang, H. Nagasawa, M. Kanezashi, T. Yoshioka and T. Tsuru; "Fabrication of Hybrid Silica Separation Layer on Porous Polysulfone Support and Application of the Multi-Layer Structured Composite Membrane to Vapor Permeation," J. Membr. Sci., 464, 140-148 (2014)

Ibrahim, S. M., R. Xu, H. Nagasawa, A. Naka, J. Ohshita, T. Yoshioka, M. Kanezashi and T. Tsuru; "A Closer Look at the Development and Performance of Organic/Inorganic Membranes Using 2,4,6-tris[3(triethoxysilyl)-1-propoxyl]-1,3,5-triazine (TTESPT)," RSC Advances, 4, 12404-12407 (2014)

Ibrahim, S. M., H. Nagasawa, M. Kanezashi and T. Tsuru; "Robust Organosilica Membranes for High Temperature Reverse Osmosis (RO) Application: Membrane Preparation, Separation Characteristics of Solutes And Membrane Regeneration," J. Membr. Sci., 493 515-523 (2015)

Igi, R., T. Yoshioka, Y. H. Ikuhara, Y. Iwamoto and T. Tsuru; "Characterization of Co-Doped Silica for Improved Hydrothermal Stability and Application to Hydrogen Separation Membranes at High Temperatures," J. Am. Ceram. Soc., 91, 2975-2981 (2008)

Kanezashi, M. and M. Asaeda; "Stability of $\mathrm{H}_{2}$-Permselective Ni-Doped Silica Membranes in Steam at High Temperature," J. Chem. Eng. Japan, 38, 908-912 (2005)

Kanezashi, M., K. Yada, T. Yoshioka and T. Tsuru; "Design of Silica Networks for Development of Highly Permeable Hydrogen Separation Membranes with Hydrothermal Stability," J. Am. Chem. Soc., 131, 414-415 (2009)

Kanezashi, M., M. Kawano, T. Yoshioka and T. Tsuru; "Organic-Inorganic Hybrid Silica Membranes with Controlled Silica Network Size for Propylene/Propane Separation," Ind. Eng. Chem. Res., 51, 944-953 (2012a)

Kanezashi, M., W. N. Shazwani, T. Yoshioka and T. Tsuru; "Separation of Propylene/Propane Binary Mixtures by bis (triethoxysilyl) Methane (BTESM)-Derived Silica Membranes Fabricated at Different Calcination Temperatures," J. Membr. Sci., 415-416, 478-485 (2012b)

Kanezashi, M., T. Sasaki, H. Tawarayama, H. Nagasawa, T. Yoshioka and T. Tsuru; "An Experimental and Theoretical Study On Small Gas Permeation Properties through Amorphous Silica Membrane," J. Phys. Chem. C, 118, 20323-20331 (2014)

Kanezashi, M., T. Matsutani, T. Wakihara, H. Tawarayama, H. Nagasawa, T. Yoshioka, T. Okubo and T. Tsuru; "Tailoring the Subnano Silica Structure via Fluorine Doping for Development of Highly Permeable $\mathrm{CO}_{2}$ Separation Membranes," ChemNanoMat, 2, 264- 
267 (2016)

Kanezashi, M., Y. Yoneda, H. Nagasawa, T. Tsuru, K. Yamamoto and J. Ohshita; "Gas Permeation Properties for Organosilica Membranes with Different Si/C Ratios and Evaluation of Microporous Structures," AIChE J., 63, 4491-4498 (2017)

Kitao, S., H. Kameda and M. Asaeda; "Gas Separation by thin Porous Silica Membrane of Ultra Fine Pores at High Temperature," MAKU (Membrane), 15, 222-227 (1990)

Kong, C., M. Kanezashi, T. Yamamoto, T. Shintani and T. Tsuru; "Controlled Synthesis of High Performance Polyamide Membrane with Thin Dense Layer for Water Desalination," J. Membr. Sci., 362, 76-80 (2010)

Kusakabe, K., S. Sakamoto, T. Saie and S. Morooka; "Pore Structure of Silica Membranes Formed by a Sol-Gel Technique Using Tetraethoxysilane and Alkyltriethoxysilanes," Separ. Purif. Technol., 16, 139-146 (1999)

Lee, H. R., M. Kanezashi, Y. Shimomura, T. Yoshioka and T. Tsuru; "Evaluation and Fabrication of Pore-Size-Tuned Silica Membranes with Tetraethoxydimethyl Disiloxane For Gas Separation," AIChE J., 57, 2755-2765 (2011)

Li, G., M. Kanezashi and T. Tsuru; "Preparation of Organic-Inorganic Hybrid Silica Membranes Using Organoalkoxysilanes: Effect of Pendant Groups," J. Membr. Sci., 379, 287-295 (2011)

Lin, H., Z. He, Z. Sun, J. Kniep, A. Ng, R. W. Baker and T. C. Merkel; " $\mathrm{CO}_{2}$-Selective Membranes for Hydrogen Production and $\mathrm{CO}_{2}$ Capture-Part II: Techno-Economic Analysis," J. Membr. Sci., 493, 794-806 (2015)

Liu, L., D. K. Wang, D. L. Martens, S. Smart and J. C. Diniz da Costa; "Interlayer-Free Microporous Cobalt Oxide Silica Membranes via Silica Seeding Sol-Gel Technique," J. Membr. Sci., 492, 1-8 (2015)

Meng, L., X. Yu, T. Niimi, H. Nagasawa, M. Kanezashi, T. Yoshioka and T. Tsuru; "Methylcyclohexane Dehydrogenation for Hydrogen Production via a Bimodal Catalytic Membrane Reactor," AIChE J., 61, 1628-1638 (2015)

Merkel, T. C., M. Zhou and R. W. Baker; "Carbon Dioxide Capture with Membranes at an IGCC Power Plant," J. Membr. Sci., 389, 441-450 (2012)

Messaoud, S. B., A. Takagaki, T. Sugawara, R. Kikuchi and S. T. Oyama; "Alkylamine-Silica Hybrid Membranes for Carbon Dioxide/Methane Separation," J. Membr. Sci., 477, 161-171 (2015)

Myagmarjav, O., A. Ikeda, N. Tanaka, S. Kubo and M. Nomura; "Preparation of an $\mathrm{H}_{2}$-Permselective Silica Membrane for the Separation of $\mathrm{H}_{2}$ from the Hydrogen Iodide Decomposition Reaction in the Iodine-Sulfur Process," Int. J. Hydrogen Energy, 42, 6012-6023 (2017)

Nagasawa, H., Y. Yamamoto, N. Tsuda, M. Kanezashi, T. Yoshioka and T. Tsuru; "Atmospheric-Pressure Plasma-Enhanced Chemical Vapor Deposition of Microporous Silica Membranes for Gas Separation," J. Membr. Sci., 524, 644-651 (2017)

Ngamou, P. H. T., J. P. Overbeek, R. Kreiter, H. M. van Veen, J. F. Vente, I. M. Wienk, P. Cuperus and M. Creatore; "Plasma-Deposited Hybrid Silica Membranes with a Controlled Retention of Organic Bridges," J. Mater. Chem. A Mater. Energy Sustain., 1, 5567-5576 (2013)

Niimi, T., H. Nagasawa, M. Kanezashi, T. Yoshioka, K. Ito and T. Tsuru; "Preparation of BTESE-Derived Organosilica Membranes for Catalytic Membrane Reactors of Methylcyclohexane Dehydrogenation," J. Membr. Sci., 455, 375-383 (2014)

Nomura, M., K. Ono, S. Gopalakrishnan, T. Sugawara and S. Nakao; "Preparation of a Stable Silica Membrane by a Counter Diffusion Chemical Vapor Deposition Method," J. Membr. Sci., 251, 151-158 (2005)
Nomura, M., T. Nagayo and K. Monma; "Pore Size Control of a Molecular Sieve Silica Membrane Prepared by a Counter Diffusion CVD Method," J. Chem. Eng. Japan, 40, 1235-1241 (2007)

Nomura, M., E. Matsuyama, A. Ikeda, M. Komatsuzaki and M. Sasaki; "Preparation of Silica Hybrid Membranes for High Temperature $\mathrm{CO}_{2}$ Separation," J. Chem. Eng. Japan, 47, 569-573 (2014)

Ohta, Y., K. Akamatsu, T. Sugawara, A. Nakao, A. Miyoshi and S.-I. Nakao; "Development of Pore Size-Controlled Silica Membranes for Gas Separation by Chemical Vapor Deposition," J. Membr. Sci., 315, 93-99 (2008)

Paradis, G. G., D. P. Shanahan and R. Kreiter; "H. M. van Veen H. L. Castricum, A. Nijmeijer and J. F. Vente; "From Hydrophilic to Hydrophobic Hybsi ${ }^{\circledR}$ Membranes: a Change of Affinity And Applicability," J. Membr. Sci., 428, 157-162 (2013)

Qi, H., H. Chen, L. Li, G. Zhu and N. Xu; "Effect of Nb Content on Hydrothermal Stability of a Novel Ethylene-Bridged Silsesquioxane Molecular Sieving Membrane for $\mathrm{H}_{2} / \mathrm{CO}_{2}$ Separation," J. Membr. Sci., 421-422, 190-200 (2012)

Raaijmakers, M. J. T., M. A. Hempenius, P. M. Schön, G. J. Vancso, A. Nijmeijer, M. Wessling and N. E. Benes; "Sieving of Hot Gases by Hyper-Cross-Linked Nanoscale-Hybrid Membranes," J. Am. Chem. Soc., 136, 330-335 (2014)

Raman, N. K. and C. J. Brinker; "Organic "Template" Approach to Molecular Sieving Silica Membranes," J. Membr. Sci., 105, 273-279 (1995)

Ren, X., K. Nishimoto, M. Kanezashi, H. Nagasawa, T. Yoshioka and T. Tsuru; " $\mathrm{CO}_{2}$ Permeation through Organic-Inorganic Hybrid Silica Membranes in the Presence of Water Vapor," Ind. Eng. Chem. Res., 53, 6113-6120 (2014)

Ren, X., M. Kanezashi, H. Nagasawa and T. Tsuru; "Plasma-Assisted Multi-Layered Coating towards Improved Gas Permeation Properties for Organosilica Membranes," RSC Advances, 5, 59837-59844 (2015)

ten Elshof, J. E. and A. P. Dral; "Structure-Property Tuning in Hydrothermally Stable Sol-Gel Processed Hybrid Organosilica Molecular Sieving Membranes," J. Sol-gel Sci. Technol., 79, 279-294 (2016)

Tsuru, T.; "Inorganic Porous Membranes for Liquid Phase Separation," Separ. Purif. Methods, 30, 191-220 (2001)

Tsuru, T.; "Nano/Subnano-Tuning of Porous Ceramic Membranes for Molecular Separation,” J. Sol-gel Sci. Technol., 46, 349-361 (2008)

Tsuru, T.; "Development of Metal-Doped Silica Membranes for Increased Hydrothermal Stability and their Applications to Membrane Reaction of Steam Reforming of Methane," J. Jpn. Petrol. Inst., 54, 277-286 (2011)

Tsuru, T., H. Takezoe and M. Asaeda; "Ion Separation by Porous SilicaZirconia Nanofiltration Membranes," AIChE J., 44, 765-768 (1998)

Tsuru, T., T. Nakasuji, M. Oka, M. Kanezashi and T. Yoshioka; "Preparation of Hydrophobic Nanoporous Methylated $\mathrm{SiO}_{2}$ Membranes and Application to Nanofiltration of Hexane Solutions," J. Membr. Sci., 384, 149-156 (2011a)

Tsuru, T., H. Shigemoto, M. Kanezashi and T. Yoshioka; “2-Step Plasma-Enhanced CVD for Low-Temperature Fabrication of Silica Membranes with High Gas-Separation Performance," Chem. Commun. (Camb.), 47, 8070-8072 (2011b)

Tsuru, T., T. Shibata, J. Wang, H. R. Lee, M. Kanezashi and T. Yoshioka; "Pervaporation of Acetic Acid Aqueous Solutions by Organosilica Membranes," J. Membr. Sci., 421-422, 25-31 (2012)

van Veen, H. M., M. D. A. Rietkerk, D. P. Shanahan, M. M. A. van Tuel, R. Kreiter, H. L. Castricum, J. E. ten Elshof and J. F. Vente; "Pushing Membrane Stability Boundaries with HybSiR Pervaporation Membranes," J. Membr. Sci., 380, 124-131 (2011)

Wang, J., G. Gong, M. Kanezashi, T. Yoshioka, K. Ito and T. Tsuru; 
"Pervaporation Performance and Characterization of Organosilica Membranes with Tuned Pore Size by Solid-Phase HCl Post-Treatment," J. Membr. Sci., 441, 120-128 (2013)

Xomeritakis, G., C. Y. Tsai and C. J. Brinker; "Microporous Sol-Gel Derived Aminosilicate Membrane for Enhanced Carbon Dioxide Separation," Separ. Purif. Technol., 42, 249-257 (2005)

Yamamoto, K., M. Kanezashi, T. Tsuru and J. Ohshita; "Preparation of Bridged Polysilsesquioxane-Based Membranes Containing 1,2,3-Triazole Moieties for Water Desalination," Polym. J., 49, 401406 (2017)

Yang, H., M. Elma, D. K. Wang, J. Motuzas and J. C. Diniz da Costa; "Interlayer-Free Hybrid Carbon-Silica Membranes for Processing Brackish to Brine Salt Solutions by Pervaporation," J. Membr. Sci., 523, 197-204 (2017)

Yoshida, K., Y. Hirano, H. Fujii, T. Tsuru and M. Asaeda; "Hydrothermal Stability and Performance of Silica-Zirconia Membranes for Hydrogen Separation in Hydrothermal Conditions," J. Chem. Eng.
Japan, 34, 523-530 (2001)

Yoshioka, T., M. Kanezashi and T. Tsuru; "Micropore size Estimation on Gas Separation Membranes: A study in Experimental and Molecular Dynamics," AIChE J., 59, 2179-2194 (2013)

Yu, L., M. Kanezashi, H. Nagasawa, J. Oshita, A. Naka and T. Tsuru; "Fabrication and Microstructure Tuning of a Pyrimidine-bridged Organoalkoxysilane Membrane for $\mathrm{CO}_{2}$ Separation," Ind. Eng Chem. Res., 56, 1316-1326 (2017)

Yu, X., L. Meng, T. Niimi, H. Nagasawa, M. Kanezashi, T. Yoshioka and T. Tsuru; "Network Engineering of a BTESE Membrane for Improved Gas Performance via a Novel Ph-Swing Method," J. Membr. Sci., 511, 219-227 (2016)

Zhang, X. L., H. Yamada, T. Saito, T. Kai, K. Murakami, M. Nakashima, J. Ohshita, K. Akamatsu and S. Nakao; "Development of Hydrogen-Selective Triphenylmethoxysilane-Derived Silica Membranes with Tailored Pore Size by Chemical Vapor Deposition," J. Membr. Sci., 499, 28-35 (2016) 